\title{
PENETRATION AND LINEAR ABSORPTION OF LOWER HYBRID WAVES IN A TOKAMAK PLASMA
}

BY

S. BERNABEI AND I, FIDONE

\section{PLASMA PHYSICS LABORATORY}

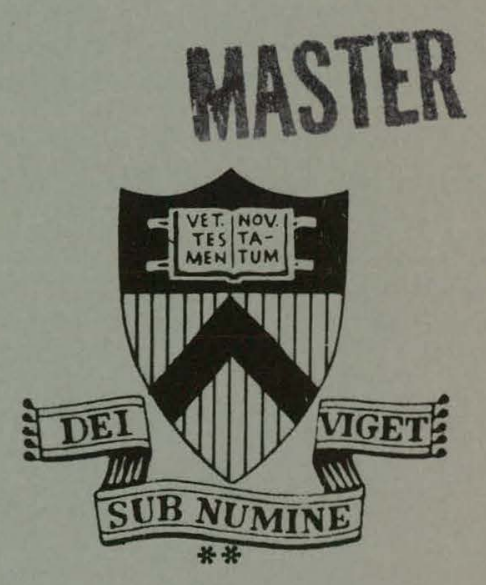

\section{PRINCETON UNIVERSITY PRINCETON, NEW JERSEY}

This work was supported by U. S. Energy Research and Development Administration Contract E(11-1)-3073. Reproduction, translation, publication, use and disposal, in whole or in part, by or for the United States Government is permitted. 


\section{DISCLAIMER}

This report was prepared as an account of work sponsored by an agency of the United States Government. Neither the United States Government nor any agency Thereof, nor any of their employees, makes any warranty, express or implied, or assumes any legal liability or responsibility for the accuracy, completeness, or usefulness of any information, apparatus, product, or process disclosed, or represents that its use would not infringe privately owned rights. Reference herein to any specific commercial product, process, or service by trade name, trademark, manufacturer, or otherwise does not necessarily constitute or imply its endorsement, recommendation, or favoring by the United States Government or any agency thereof. The views and opinions of authors expressed herein do not necessarily state or reflect those of the United States Government or any agency thereof. 


\section{DISCLAIMER}

Portions of this document may be illegible in electronic image products. Images are produced from the best available original document. 


\section{NOTICE}

This report was prepared as an account of work sponsored by the United States Government. Neither the United States nor the United States Energy Research and Development Administration, nor any of their employees, nor any of their contractors, subcontractors, or their employees, makes any warranty, express or implied, or assumes any legal liability or responsibility for the accuracy, completeness or usefulness of any information, apparatus, product or process disclosed, or represents that its use would not infringe privately owned rights.

Printed in the United States of America.

Available from

National Technical Information Service

U. S. Department of Commerce 5285 Port Royal Road

Springfield, Virginia 22151

Price: Printed Copy \$_; Microfiche $\$ 1.45$

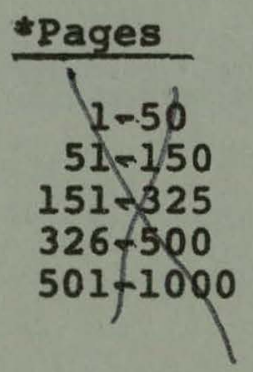

NTIS

Selling Price

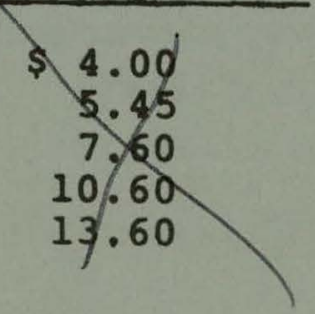




\section{PENETRATION AND LINEAR ABSORPTION \\ OF LOWER HYBRID WAVES IN A TOKAMAK PLASMA ${ }^{+}$ \\ S. Bernabei and I. Fidone \\ Ṕlasma Physics Laboratory, Princeton University \\ Princeton, New Jersey 08540}

\section{ABSTRACT}

Penetration and linear absorption of slow waves in a hot tokamak plasma is studied for waveguide coupling. For this coupling system, the emphasis is placed on the role of the plasma density profile facing the waveguides over the spectrum of the energy flux launched. This spectrum consists of three portions: a first portion $\left(l<\left|n_{n}\right|<\left|n_{n}{ }^{\star}\right|\right)$, is likely to be trapped in the outer part of the plasma and might be responsible for absolute parametric instability. A second portion $\left(\left|n_{n}{ }^{*}\right|<\left|n_{n}\right|<\left|n_{n L}\right|\right)$, penetrates deep into the plasma and may be absorbed by ions via ion-cyclotron or perpendicular Landau damping after being converted into short wavelength Bernsteinlike modes. The remaining portion $\left(\left|n_{n}\right|>\left|n_{1 L}\right|\right)$, is generally absorbed by electrons via electron Landau damping before reaching the region of lower hybrid wave conversion.

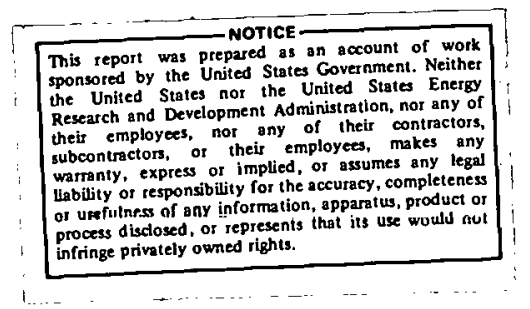

†Presented at the Third International Symposium on Plasma Heating in Toroidal Devices, 6-17 September 1976, Varenna, Italy.

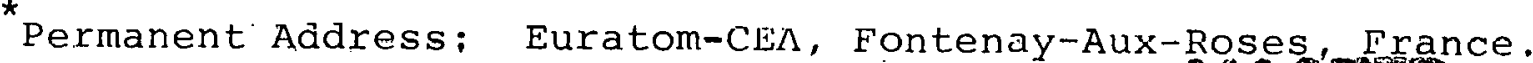

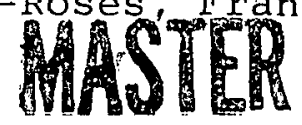




\section{INTRODUUCTION}

In recent: years there has been a great deal. of interest in using waveguides as a launching structure of wave energy in a Tokamak plasma. In the frequency range of few GHz the results obtained by properly phased waveguides in an open ended linear. device, ${ }^{1}$ have been very encouraging. Very good coupling is found and no dangerous effecte at the plasma edye asc seen, as for instance strong parametric instability or gas breakdown. However, the measured energy distribution shows a poor localization of the wave-front. This may suggest that a fraction of the energy propagating into the plasma is reflected back towards the plasma edge. In a closed toroidal machine, this energy accumulates between the metallic chamber and the plasma within a distance of a few centimeters and can be responsible for: unwanted absolute parametric instability. It is therefore important to seek for conditions of best wave penetration according to the linear theory of plasma-waveguides coupling. 2 This is done by calculating the spectrum of the energy flux as a function of the refractive index, $n_{\prime \prime}$, for given plasmawaveguides parameters. As well-known, the portion of the spectrum with $n_{11}{ }^{2} \leq\left(1 ;-\omega^{2} / \omega_{c i}\left|\omega_{c e}\right|\right)^{-1}$, (where $\omega$ is the wave frequency and $w_{c}$ the cyclotron frequency), is reflected by the plasma towards the boundaries. In particular, the plasma region where 
$\left.\omega=\omega_{L H}=\omega_{\mathrm{pi}} /\left(1+\omega_{\mathrm{pe}}^{2} / \mu\right)_{\mathrm{ce}}^{2}\right)^{1 / 2}$ is not accessible to that part of the spectrum with $\mathrm{n}^{2}{ }^{2} \leq 1+\left(\omega^{2} \mathrm{pe}^{/ \mu)^{2}} \mathrm{ce}\right)_{\mathrm{LH}}$. The spectrum of energy which penetrates deep into the plasma is used to calculate the energy released to the electrons and ions via collisionless electron Landau and ion cyclotron damping.

\section{COUPLING OF THE SLOW AND FAST WAVES}

In the usual slab geometry, with the density gradient normal to the slab face (the $x$-direction) and the direction of the confining magnetic field parallel to the slab face (the z-direction), the dispersion relation for the two cold plasma normal modes is

$$
\begin{gathered}
\varepsilon_{\mathrm{xx}} \mathrm{n}_{\perp}^{4}-\mathrm{n}_{\perp}^{2}\left[\varepsilon_{\mathrm{xy}}^{2}+\left(\varepsilon_{\mathrm{xx}}+\varepsilon_{\mathrm{zz}}\right)\left(\varepsilon_{\mathrm{xx}}-\mathrm{n}_{11}{ }^{2}\right)\right] \\
+\varepsilon_{\mathrm{zz}}\left[\left(\varepsilon_{\mathrm{xx}}-\mathrm{n}_{n}{ }^{2}\right)^{2}+\varepsilon_{\mathrm{xy}}^{2}\right]=0
\end{gathered}
$$

where $\varepsilon_{i j}$ are the components of the permittivity tensor and the propagation. vector is written as $\vec{k}=(\omega / c)\left(n_{\perp} \vec{e}_{X}+n_{n} \vec{e}_{z}\right)$. For values of the plasma parameters for which the two roots of.Eq. (1) are equal, the two modes couple to one another. At the coupling point we have

$$
\omega_{p i}=\omega\left[n_{\prime \prime} \frac{\omega}{\omega_{c j}\left|\omega_{c e}\right|} \pm \sqrt{1+n_{n}{ }^{2}\left(\frac{\omega)^{2}}{\omega_{c i}\left|\omega_{c e}\right|}-1\right)}\right] .
$$

Thus, for $n_{1}{ }^{2} \leq\left(1-\dot{\omega}^{2} / \omega_{c i} \mid \omega_{c e}\right)^{-1}$, the slow mode will couple to a fast mode in the region where Eq. (2) holds and propogates 
towards the low density region up to the reflection point. This is shown qualitatively in Fig. 1. As a result of the bouncing back and forth between the metallic chamber and the coupling point, this part of the energy spectrum accumulates in the low density side of a toroidal plasma. As a result of the increasing amplitude of the trapped waves we expect parametric absolute instability at the plasma periphery. The location of the coupling point is obtained from Eq. (2).

In Fig. $2(a):(b)$ we plot the coupling density versus magnetic

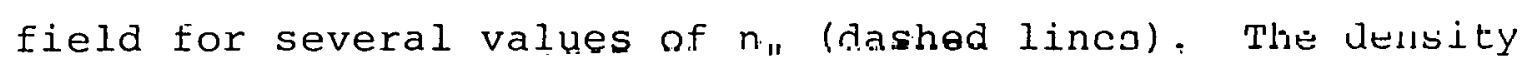
profile is also presented and the intersection with the dashed lines corresponaing to a given $n_{\|}$, yields the values of the density at which the slow mode coupies with the fast mode. The minimum value of $n_{n}$ for which there is no intersection defines the portion of the spectrum which is reflected towards the boundaries.

\section{TTT. SPECTRUM OF TIIE ENERGY FLUX}

Since the waves with $n_{n}{ }^{2}<1$ do not. propagate at all into the plasma, for the field of the slow wave in the low density region we have

$$
\begin{aligned}
& E_{z}=\int_{-\infty}^{\infty} a k_{n} i_{z}\left(k_{n,}, x\right) \exp { }^{i k_{n} z}, \\
& B_{y}=\int_{-\infty}^{\infty} d k_{1,} B_{y}\left(k_{11} \cdot x\right) \exp i k_{i z},
\end{aligned}
$$


where $\mathrm{x}$ is an arbitrary point corresponding to the radial dimension in the plasma and the bar in the integral means that the range $\left(-k_{0}, k_{0}=\omega / c\right)$ is not considered. We also have and

$$
E_{y}=0, E_{x}=i \frac{k_{11}}{k_{\perp}^{2}} \frac{d E_{z}}{d x}, B_{y}=i \frac{k_{0}}{k_{\perp}^{2}} \frac{d E_{z}}{d x}, B_{x}=B_{z}=0 \text {, }
$$

$$
\frac{d^{2} E_{z}}{d x^{2}}+k_{\perp}^{2} \cdot \varepsilon_{z z} E_{z}=0
$$

where $k_{\perp}{ }^{2}=k_{0}{ }^{2}-k_{n}{ }^{2}<0$. The total flux of energy entering the plasma at $\mathrm{x}$ is given by

$$
S_{x}=-\frac{c}{8 \pi} L_{y} \int_{-\infty}^{\infty} d z \operatorname{Re} E_{z} B_{y}^{*}=f_{-\infty}^{\infty} d n_{n} S\left(n_{n}\right),
$$

where $\mathrm{L}_{\mathrm{y}}$ is defined by the dimension of the coupling structure in the $y$-direction and

$$
S\left(n_{11}\right)=-\left(k_{\circ} L_{y}\right) \frac{C}{4}-\operatorname{Re} E_{z}\left(k_{11}, x\right) B_{y}^{*}\left(k_{11}, x\right) .
$$

Now, in the region where $\omega_{\text {pe }}^{2}>\omega^{2}$ we have

$$
E_{z}\left(k_{n}, x\right)=A\left(n_{n}\right) n_{x}^{-1 / 2} \exp \left(-i k_{0} \int^{x} n_{x} d x\right)
$$

where $n_{x}^{2}=\left(n_{11}^{2}-1\right)\left(-\varepsilon_{z z}\right)>0$, thus

$$
S\left(n_{n}\right)=\left(k_{0} L_{y}\right) \frac{c}{4} \frac{\left|A\left(n_{n}\right)\right|^{2}}{n_{n}^{2}-1}
$$


where $A\left(n_{n}\right)$ is determined by the properties of the slow-wave structure and by the plasma density profile at the plasma edge. The presence of $n_{n}{ }^{2}-1$ in the denominator of Eq. (9) suggests that $S\left(n_{n}\right)$ might be peaked near $n_{n}{ }^{2} \approx 1$, unless $\left|A\left(n_{n}\right)\right|^{2}$ tend's to zero as $n_{n}{ }^{2} \rightarrow 1$. To evaluate $A\left(n_{n}\right)$ we need to specify the structure of the plasma facing the waveguide. Of course, this is difficult to do since the local plasma might be determined by the waveguide and the amplitude of the electromagnetic field at the plasma-vacuum interface. . We can only calculate $A\left(n_{n}\right)$ for special models. We first note that the density at which $\omega_{\text {pe }}=\omega \approx 2 \pi \mathrm{Gz}$ is about $10^{10} \mathrm{~cm}^{-3}$. A residual density of $10^{10}-10^{11}$ is likely to exjst at the boundary of a Tokamak plasma. Therefore, a possibly realistic model is that of a waveguide facing, a plasma wall of density greater or equal to the cut-off density. Let $x=0$ be the location of the plasma-waveguide interface. For $x=0^{+}$we have

$$
E_{z}\left(k_{n}, x\right)=A\left(n_{n}\right) n_{x}^{-1 / 2} \exp \left(-i k_{0} \int_{0}^{x} n_{x} d x\right), B_{y}(k n, x)=-\frac{n_{x}}{n_{n}^{2}-1} E_{z^{\prime}},
$$

where $n_{x}^{2}=n^{2}\left(n_{n}^{2}-1\right)>0$ and $n^{2}=\frac{\omega_{p e}^{2}}{\omega^{2}}-1$. Fnr $x=n^{-}:$we write

$$
\begin{aligned}
E_{z}\left(k_{1}, x\right) & =\sigma\left(n_{n}\right) \exp \left(i k_{\perp} x\right)-\gamma\left(n_{n}\right) \sigma\left(n_{n}\right) \exp \left(-i k_{\perp} x\right), \\
B_{Y}\left(k_{n}, x\right)= & i \frac{1}{\sqrt{n_{n}^{2}-i}}\left[\sigma \exp \left(i k_{\perp} x\right)-\gamma \sigma \exp \left(i k_{\perp} x\right)\right]
\end{aligned}
$$

From the continuity of $E_{z}, B_{y}$ at $x=0$ we have 


$$
\begin{gathered}
r=-\frac{1-i n_{0}}{1+i n_{0}}, \\
A\left(n_{n}\right)=\frac{2 o\left(n_{1}\right) n_{x} 1 / 2}{1+i n_{0}},
\end{gathered}
$$

and

$$
S\left(n_{n}\right)=\left(k_{0} L_{y}\right) c \frac{\left|\sigma\left(n_{n}\right)\right|^{2}}{\sqrt{n_{n}{ }^{2}-1}} \frac{n_{0}}{1+n_{0}^{2}} \text {. }
$$

where $\eta_{0}=n(x=0)$ and $\sigma\left(n_{11}\right)$ is determined by matching Eqs. (10) and (11) with the waveguide field. ${ }^{2}$

If the residual plasma at the boundaries can be made arbitrarily small it seems reasonable to assume that the plasma density be negligible up to a distance $x_{p}$ from the waveguide and increasing linearly for $x>x_{p}$. Letting ${ }^{2}$

$$
\varepsilon_{z z}=1-\frac{\omega_{p e}^{2}(x)}{\omega^{2}}=1-\frac{x-x_{p}}{\ell}, z=\alpha\left(\frac{x-x_{p}}{\ell}-1\right), \alpha^{3 / 2}=\left(\left|k_{\perp}\right| \ell\right),
$$

Eq. (5) becomes

$$
\frac{d^{2} E_{z}}{d z^{2}}+z E_{z}=0
$$

The solution of $\mathrm{Eq}$. (15), which represents a backward wave in the region where $x-x_{p}>l$, is given by

$$
E_{z}=b\left[B_{i}(-z)-i A_{i}(-z)\right] \text {. }
$$

Using Eqs. (10 and (11) at $\mathrm{x}=\mathrm{x}_{\mathrm{p}}$ we obtain

$$
|b|^{2}=2 \pi \alpha^{1 / 2}\left|\sigma\left(n_{n}\right)\right|^{2} \operatorname{Im} \gamma\left(n_{n}\right) \text {, }
$$




$$
S\left(n_{! \prime}\right)=\left(k_{0} L_{y}\right)-\frac{c\left|g\left(n_{n}\right) \cdot\right|^{2} \operatorname{Im} \gamma\left(n_{n}\right)}{2 \sqrt{n_{n !}^{2}-1}}
$$

where

$$
\begin{aligned}
& \gamma\left(n_{11}\right)=\exp \left(-2\left|k_{\perp}\right| x_{p}\right) \frac{1-Z}{1+z}, \\
& Z=\frac{I_{1 / 3}(\zeta)+\exp \left(-x_{\pi} \pi / 3\right) I_{-1 / 3}(\zeta)}{I_{-2 / 3}(\zeta)+\exp (-i \pi / 3) I_{2 / 3}(\zeta)},
\end{aligned}
$$

and $\zeta=(2 / 3) \alpha^{3 / 2}$.

In Fig. 3 we represent Eq. (18) for two and four waveguides for $\mathrm{dn} / \mathrm{dx}=\mathrm{n}_{\mathrm{c}} / \ell=10^{12} \mathrm{~cm}^{-4}$, where $\mathrm{n}_{\mathrm{c}}$ is the cut-off density. Each waveguide has dimensions $4 \times 15 \mathrm{~cm}^{2}$ : and the phase difference between two adjacent waveguides is $180^{\circ}$. From Fig. 2(a), (b) we see that, for the chosen density profile, waves with $\mathrm{n}_{n} \lesssim \mathrm{n}_{n}{ }^{*} \approx 1.5(1.8)$ are reflected towards the plasma boundaries. Now in the case of two waveguides a large fraction of the wave energy lieg in the range $1<n_{n}<n_{n}^{*}$, therefore, we can expegt that most of the wave energy is trapped in the outer region of the plasma. For four waveguides, the portion of the spectrum with $\mathrm{n}_{n}=\mathrm{n}_{\|}$" is much reduced with respect to the case of the two waveguides and we expect that most of the energy penetrates deep into the plasma. In Fig. 4(a), (b) we show the effecl or varying $x_{p}\left(a n_{o} / d x=10^{12} \mathrm{~cm}^{-4}\right)$ and $a_{0} / d x\left(x_{p}=0\right)$ on the energy spectrum for four waveguides. The corresponding: reflection coefficient in the waveguides is shown in Fig. 5. We see that for large $x_{p}$ and sharp gradients:we have important reflection and the yseful portion of the spectrum $\left(\left|n_{n}\right|>\left|n_{n}^{*}\right|\right)$ is much reduced. 


\section{ELECTRON LANDAU DAMPING}

From Fig. 3 we see that for four waveguides a nonnegligible portion ( 25\%) of the wave energy is distributed over $n_{n}>3.0$ and therefore, in a plasma with the electron temperature in the $\mathrm{keV}$ range, we expect very efficient Landau damping. The power absorption between $x_{0}$ and $x$ is given by

$$
w=\int_{-\infty}^{\infty} \operatorname{dn}{ }_{n} s\left(n_{n,}, x_{0}\right)\left[1-\exp \left(-2 \int_{x_{0}}^{x} k_{x}^{\prime \prime} d x\right)\right] \text {, }
$$

where $s\left(n_{n}, x_{0}\right)$ is given by Eqs. (14) and (18) and $k_{x}$ is obtained from the equation

$$
\mathrm{k}_{\mathrm{x}}^{2} \varepsilon_{\mathrm{xx}}-\mathrm{k}_{n}^{2}\left(\omega_{\mathrm{pe}}^{2} / \omega^{2}\right)+\mathrm{i} \varepsilon_{\mathrm{e}}=0
$$

where $k_{x}=k_{x}^{\prime}+i k_{x}^{\prime \prime} v_{e}^{2}=T_{e} / m_{e} \quad$ and

$$
\varepsilon_{e}=(\pi / 2)^{1 / 2} \frac{\omega_{p e}^{2}}{v_{e}^{2}} \frac{\omega}{\left|k_{n}\right| v_{e}} \exp \left(-\omega^{2} / 2 k_{n}{ }^{2} v_{e}^{2}\right)
$$

The bar in the integral (2l) meals that the range $\left(-n_{n}^{*}, n_{n}^{*}\right)$, where $n_{\|}^{*}$ is the minimum value of $n_{n}$ for. which there is no coupling with the fast wave, is excluded. Solving Eq. (22) we obtain

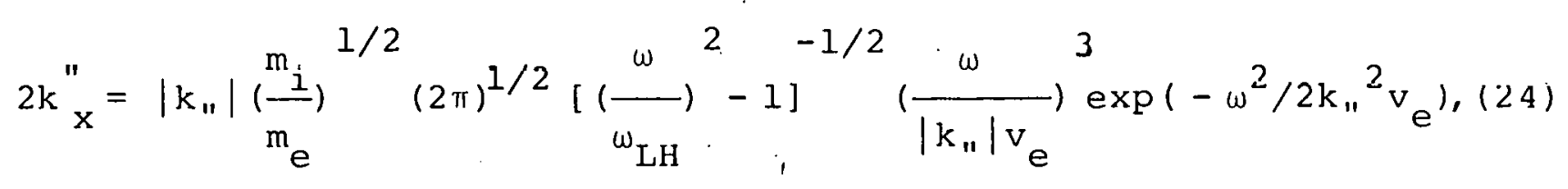

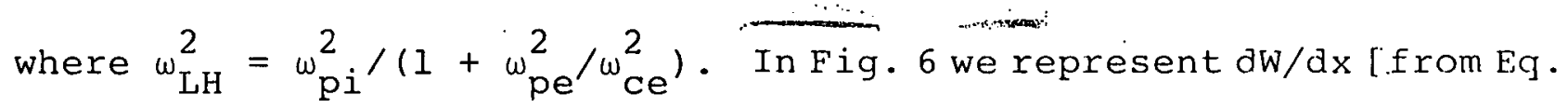
(21)] versus $x$ for the calculated spectrum (Fig. 3) and the temperature 
and density profiles shown. It is seen that the wave energy is transferred to the plasmạ electrons at $1 / 3$ of the radius from the center. A change in the phase difference of the adjacent waveguides will shift the maximum of the energy spectrum towards lower $\mathrm{n}_{\|}$and the damping will occur closer to the center. It is worth to note that the energy deposition is very sensitive to the temperature profile.

\section{COLLISIONLESS TON AASORP'ITON NEAR THE LOWER HYRRTI RFSSNANEE}

That portion of the energy spectrum which is not reflected or electron Landau damped penetrates deep into the plasma and might be converted into short wavelength Bernstein-like ${ }^{3}$ modes if the plasma parameters are such that

$$
{\stackrel{\omega}{\omega_{L H}}}^{2}=1+\frac{3}{\mathrm{~b}}
$$

where

$$
{ }^{a 1}{ }_{\mathrm{LH}}^{2}=\omega_{\mathrm{pi}}^{2} /\left(1+\omega_{\mathrm{pe}}^{2} \cdot \omega^{2}\right), \quad b=\frac{3^{1 / 2}}{2} \frac{c}{\left|\mathrm{n}_{\|}\right|\left(T_{i} / \mathrm{m}_{e}\right) 1 / 2} !
$$

The aamping of the converted wave is described by $I_{m} k_{x}$ where $k_{x}$ is obtained from the equation

$$
\lambda_{\text {th }}^{2} k_{x}^{4} \vdots-\varepsilon_{x x} k_{x}^{2}+k_{n}^{2}\left(\omega_{p e}^{2} / \omega^{2}\right) \doteq i \varepsilon_{i}=0,
$$

where 
$\varepsilon_{i}=\pi\left(\frac{\omega_{\mathrm{p}}^{2}}{v_{i}^{2}}\right)\left(\frac{\omega^{\omega}}{\omega_{C i}}\right)\left(2 \pi \lambda_{n}\right)-1 / 2 \sum_{n} \cdot I_{n}\left(\lambda_{\perp}\right) \exp \left(-\lambda_{\perp}\right) \exp \left[-\left(n-\frac{(1)}{\omega_{C i}}\right) / 2 \lambda_{n}\right]$,

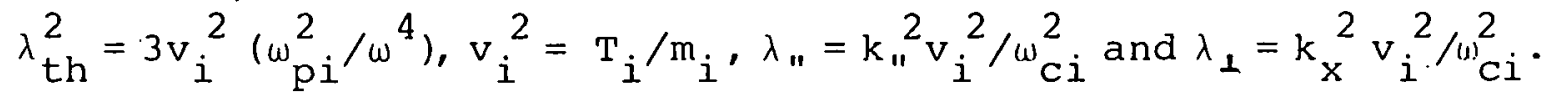

Since $\lambda_{11} \ll 1$, we have appreciable damping for $\left.\mid \omega / \omega\right)_{C i}-m \mid<<1 / 2$, where $\mathrm{m}$ is the nearest integer to $\omega / \omega_{\mathrm{Ci}}$. The solution of Eq. which describes the converted wave is

$$
k_{x}^{2}=k_{c}^{2}\left[x+\left(x^{2}-1+i \delta\right)^{1 / 2}\right]
$$

where

$$
\begin{aligned}
& \left.x=1+\frac{b}{3}\left[\left(\frac{a)}{\omega_{L H}}\right)-\left(1+\frac{3}{b}\right)\right], k_{C}^{2}=\underset{3}{2} \frac{2 b}{3}\right) k_{n}^{2}\left(m_{i} / m_{e}\right), \\
& \delta=\left(\frac{4 \pi}{3}\right) b^{2}\left(\omega / \omega_{C i}\right) I_{m}\left(\lambda_{\perp}\right) \exp \left(-\lambda_{\perp}\right)\left(2 \pi \lambda_{n}\right)-1 / 2 \exp \left[-(m-\omega /(1) c i)^{2} / 2 \lambda_{11}\right],
\end{aligned}
$$

aria $\lambda_{\perp}=\left[x+\left(x^{2}-1\right)^{1 / 2}\right]\left(\omega / \omega_{c i}\right)^{2} / 2 b$. Equation (28) is valid for $\delta \ll 1$. Letting $k_{x}=k_{x}^{\prime}+i k_{x}^{\prime \prime}$ from Eq. (28) we obtain

$$
\begin{gathered}
2 \int_{X_{0}}^{x_{2 i}} k^{\prime \prime} d x=(2 \pi / 3) k_{c} b^{2}\left(\omega / \omega_{c i}\right)\left[x+\left(x^{2}-1\right)^{1 / 2]^{-1 / 2}\left(x^{2}-1\right)^{-1 / 2}}\right. \\
x I_{m}\left(\lambda_{\perp}\right) \exp \left(-\lambda_{\perp}\right)\left(2 \pi \lambda_{n}\right)^{-1 / 2} \int_{x_{0}}^{x_{1}} d x \exp \left[-\left(m-\omega / u_{c i}\right)^{\left.2 / 2 \lambda_{1}\right],}\right.
\end{gathered}
$$

where $x^{2}-1 \gg \delta$ and $x(x)$ is assumed constant within the range of integration. We now assume

$$
\omega_{C i}(x)=\omega_{C i}\left(x_{c}\right)+\left(x-x_{C}\right)\left(d \omega_{C i} / d x\right),
$$

where $x_{c}$ is defined by the relation $\omega=m \omega_{c i}\left(x_{c}\right)$ and $x_{0}<x_{e}<x_{1}$, thus 


$$
m-\omega) / \omega_{c i}=\left(\omega / \omega_{C i}\right)\left(x-x_{C}\right) / l_{C},
$$

where $\ell_{c}^{-1}={ }^{-}\left(\mathrm{d}\left({ }_{\mathrm{Ci}} / \omega_{\mathrm{ci}} \mathrm{dx}\right)\right.$, and

$$
\begin{aligned}
2 \int_{x_{0}}^{x} k_{x} d x & =\left(3 / \pi^{1 / 2}\right)\left(m_{i} / m_{e}\right)^{1 / 2} \cdot n_{i} f(2 \pi b / 3)^{5 / 2}\left(\ell / \lambda_{0}\right) \\
\vdots & \\
x[\dot{x} & \left.+\left(x^{2}-1\right)^{1 / 2}\right]^{-1 / 2}\left(x^{2}-1\right)^{-1 / 2} I_{m}\left(\lambda_{\perp}\right) \exp \left(\div \lambda_{\perp}\right),
\end{aligned}
$$

where $\lambda_{0}$ is the vacuum wavelenqth. It is worth noting that for large $\mathrm{m}$ and $\lambda_{\perp} / \mathrm{m} \gg 1$ we have

$$
I_{m}\left(\lambda_{\perp}\right) \exp \left(-\lambda_{\perp}\right) \approx\left(2 \pi \lambda_{\perp}\right)^{-1 / 2} \exp \left(-\omega^{2} / 2 \mathrm{k}_{\mathrm{x}}^{2} \mathrm{v}^{2}\right)
$$

and Eq. (29) is similar.to the corresponding result obtained by describing the ion orbit as a straight line. 4 In the absence of damping in the conversion region $[x \approx 1]$ we have ${ }^{3}$ $S_{C}\left(n_{11}\right)=G\left(n_{11}\right)$, where $S_{C}\left(n_{11}\right)$ is the $x$-component of the converted wave, and the power absorbed by the ions is given by Eqs. (21) and (29). For plasma parameters of interest it is found that $2 \int \mathrm{k}_{\mathrm{x}} \mathrm{dx} \gg 1$ which indicates that once converted the wave energy is totally absorbed near $x_{c}$, where $x_{c}$ is the first ion cyclotron layer encountered by the converted waves.

\section{CONCLUSIONS}

We have investigated the penetration and the linear absorption of the slow wave energy flux launched by waveguides 
into a Tokamak plasma. We have found that the spect.rum is generally made by three portions. A first portion, with $1<\left|n_{n}\right|<\left|n_{n}^{*}\right|$, is likely to be trapped at the plasma periphery as a result of multiple reflections and conversion into fast modes. This fraction of the wave field may act as a pump to drive absolute ion cyclotron or acoustic wave instability which can transfer energy to the ions located at the outer part of the plasma. A second portion, with $\left|n_{11}\right|>n_{1 L} \approx 3.0$, propagates into the main body of the plasma and is Landau absorbed by electrons. We may also expect parametric decay but the threshold for spatial amplification is generally high since it is determined by convection along the $z$-direction. That portion of the energy spectrum with $\left|n_{n}^{*}\right|<\left|n_{n}\right|<\left|n_{\| L}\right|$, penetrates deep into the plasma and might be converted into short wavelength plasma modes which are strongly absorbed by ions via cyclotron or perpendicular Landau damping. The relative magnitude of the three portions is strongly dependent on the properties of the waveguides, as for instance the number and the dimensions of the waveguides and the phase difference between two adjacent waveguides, and the plasma density profile facing the launching structures. Moreover, it is possible that, in addition to the slow mode, the waveguides excite surface waves, or coaxial modes, and, therefore, a small reflection in the waveguides does not necessarily mean that all the energy leaving the waveguide is coupled with the slow modes into the plasma. 


\section{ACKNOWLEDGMENTS}

It is a pleasure to thank W. M. Hooke and R. W. Motiey

for useful discussions.

This work was supported by the United States Energy Research and Development Administration, Contract E (11-1)-3073. 


\section{REFERENCES}

${ }^{1}$ S. Eiernabei, M. A. Heald, W. M. Hooke, and F. J. Paoloni, Phys. Rev. Lett. 34,866 (1975).

${ }^{2}$ M. Brambilla, Nucl. Fusion 16, 47 (1976).

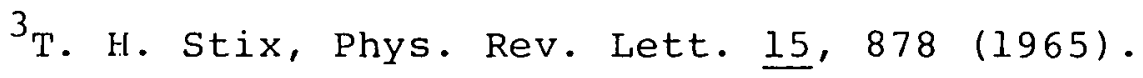

${ }^{4}$ I. Fidone, Phys. Fluids 19, 334 (1976). 


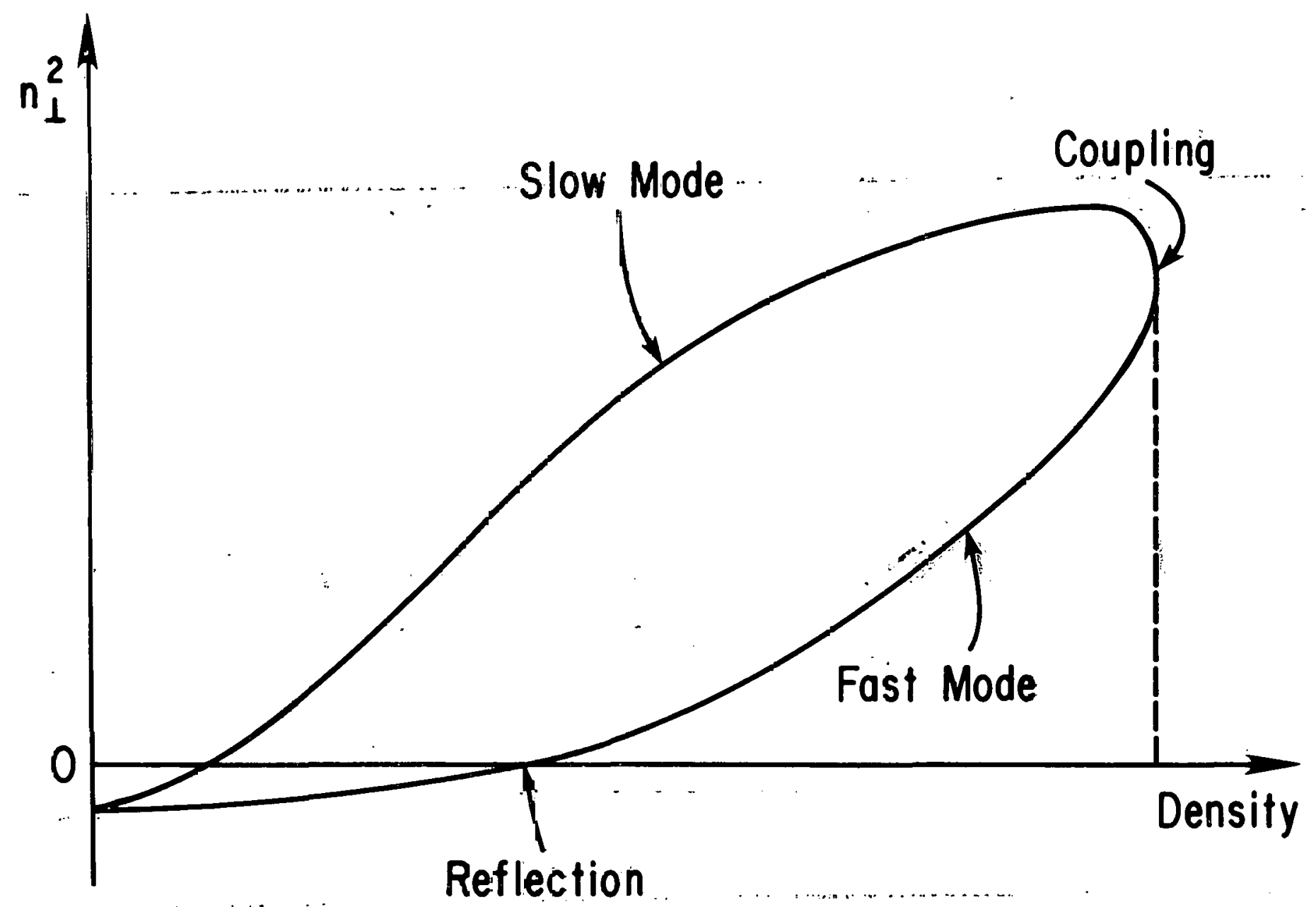

F-g. 1. Perpendicular index of refrastion squared as a function of plasma density for a farallel index of refraction iess than
$\left.i 1+\omega_{\mathrm{pe}}^{2} / \omega_{\mathrm{ce}}^{2}\right) 1 / 2$. 


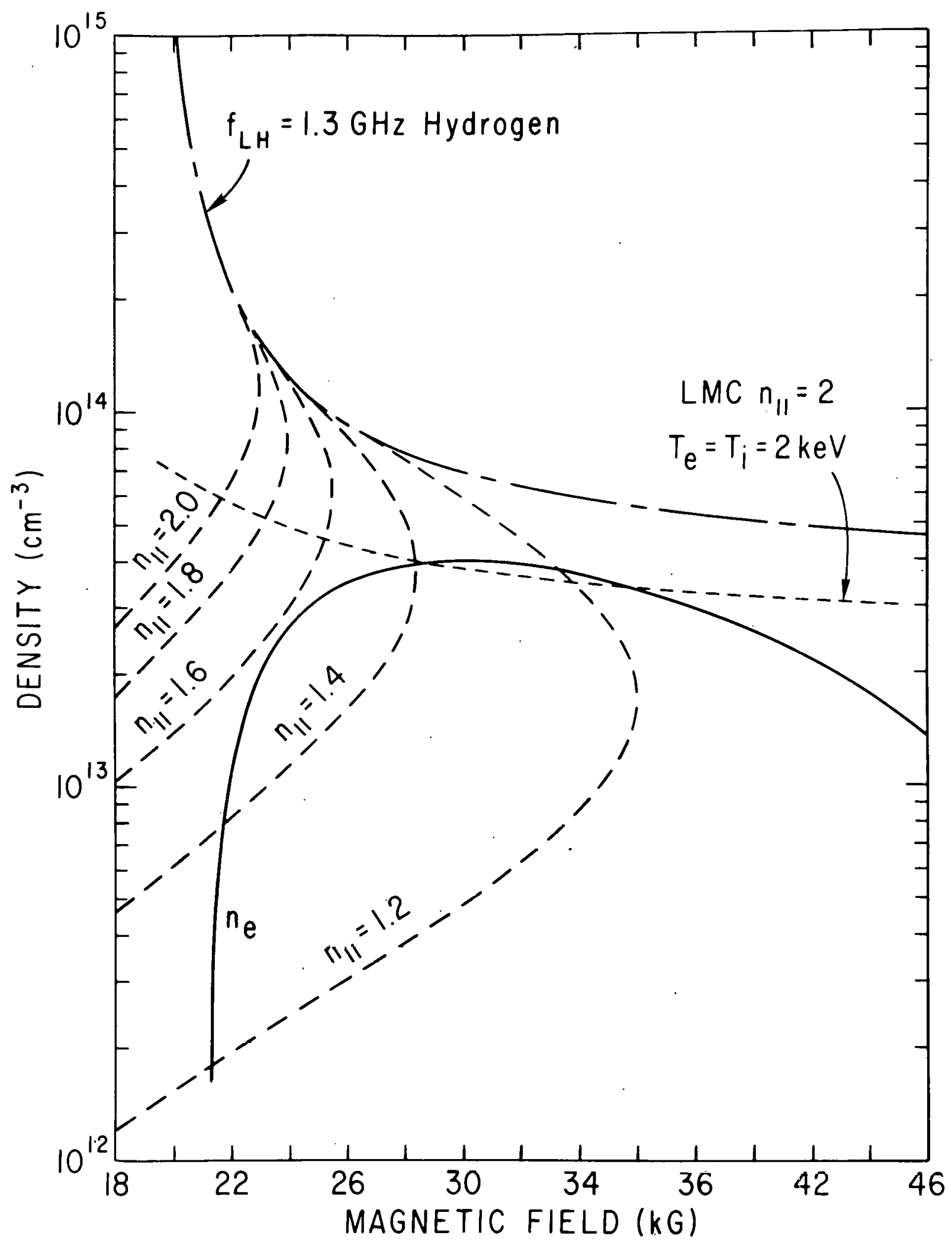

Fig. 2(a). The lower hybrid resonance for $1.3 \mathrm{GHz}$ as a function of density and magnetic field in a hydrogen plasma (broken line), a parabolic density profile (solid line), fast and slow waves coupling densities for several values of $n_{\|}$(dashed lines). The density and magnetic field at which linear mode conversion occurs for $\mathrm{n}_{n}=2$ and $\mathrm{T}_{\mathrm{e}}=\mathrm{T}_{\mathrm{i}}=2 \mathrm{ke}$ is also plotted. 


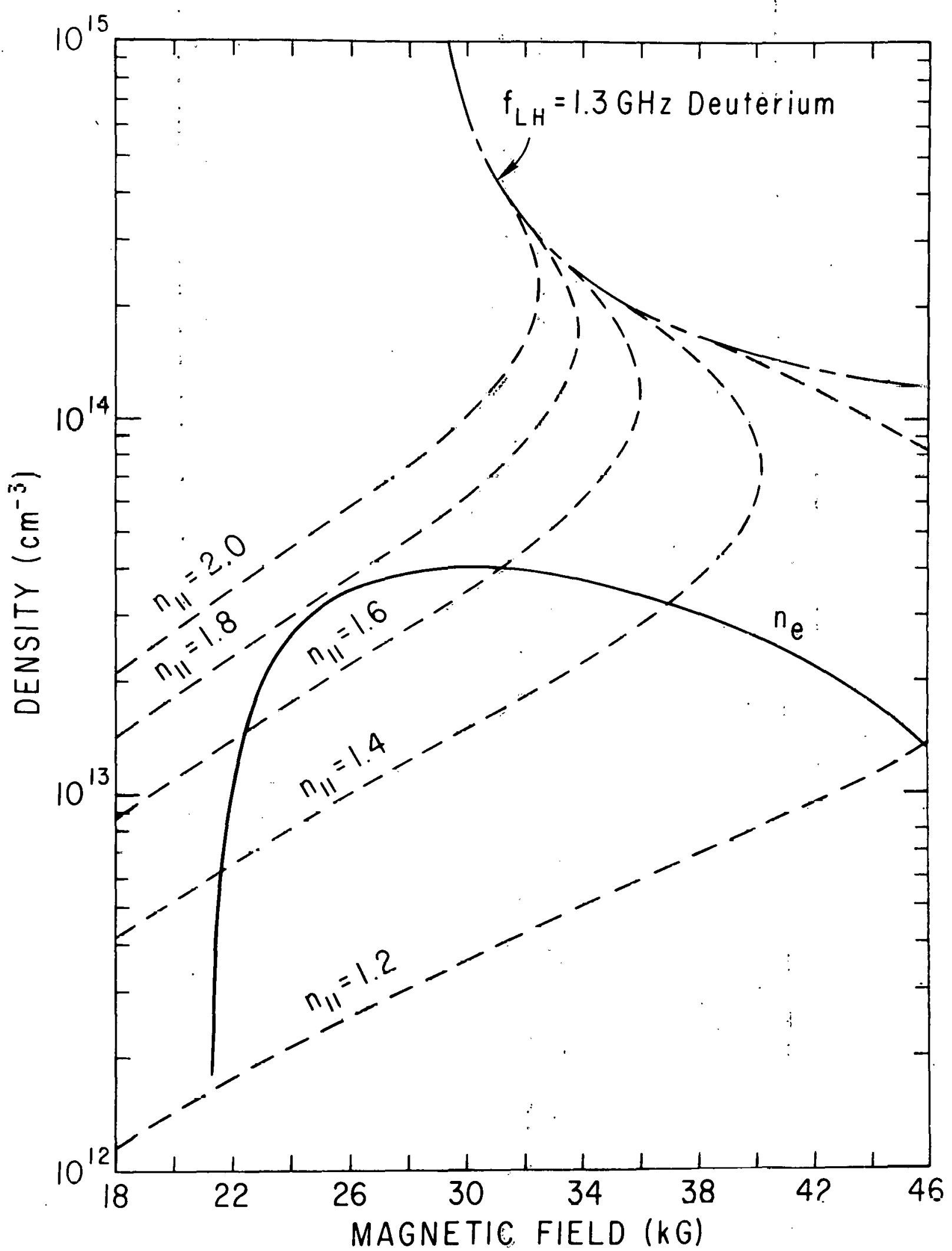

763472 plot.

Fig. 2(b). Similar plot as Fig. $2(a)$ except for a deuterium 


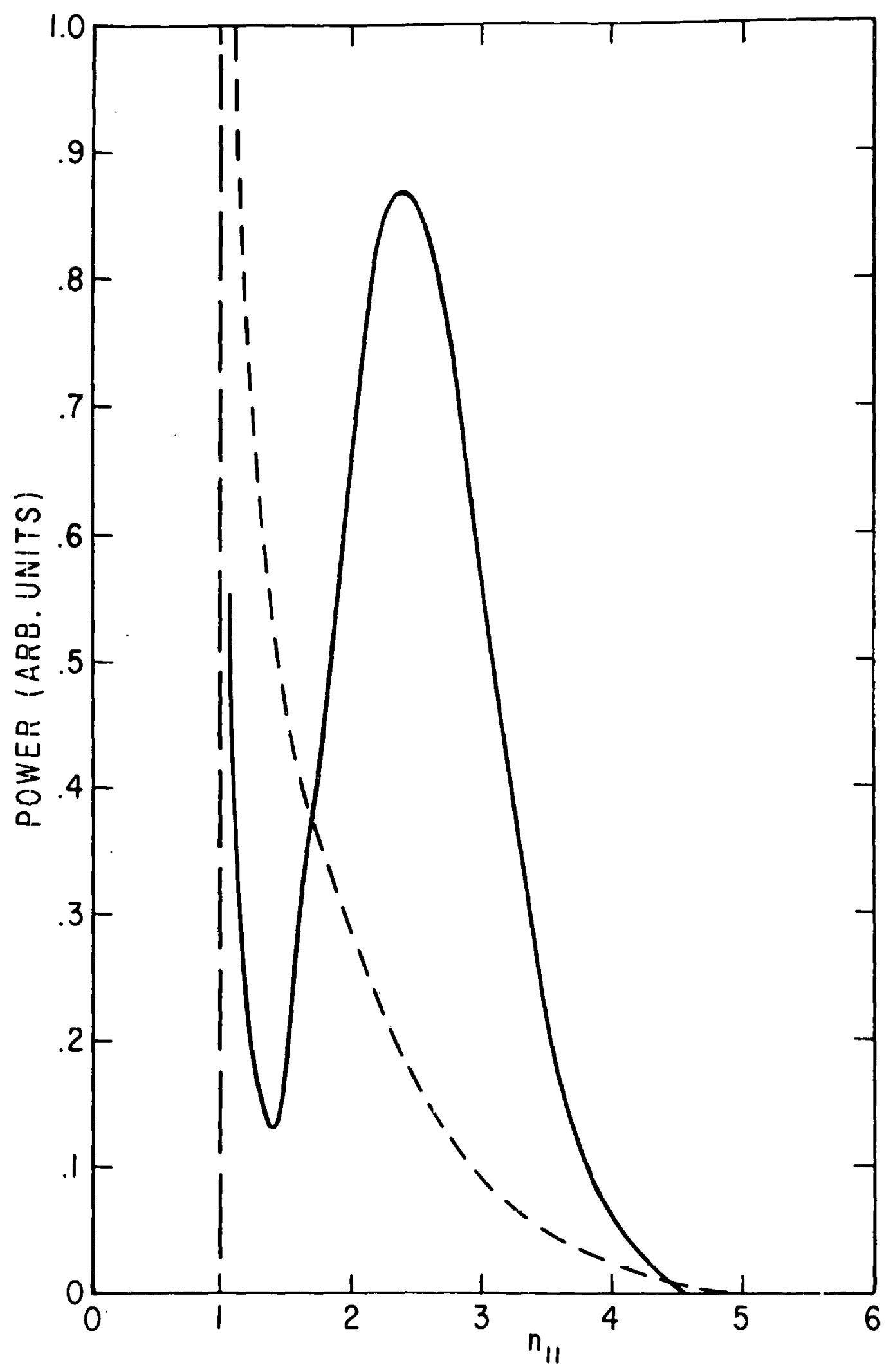

763473

Fig. 3. Energy flux spectrum radiated into the plasma by 2 waveguides (dashed line) and 4 waveguides (solid line) according to Eq. (18); dimensions of each waveguide are $4 \mathrm{~cm} \times 15 \mathrm{~cm}$, $\left(\mathrm{dn} / \mathrm{dx}=10 \div 2 \mathrm{~cm}^{-4}, \mathrm{x}_{\mathrm{p}}=0\right)$. 


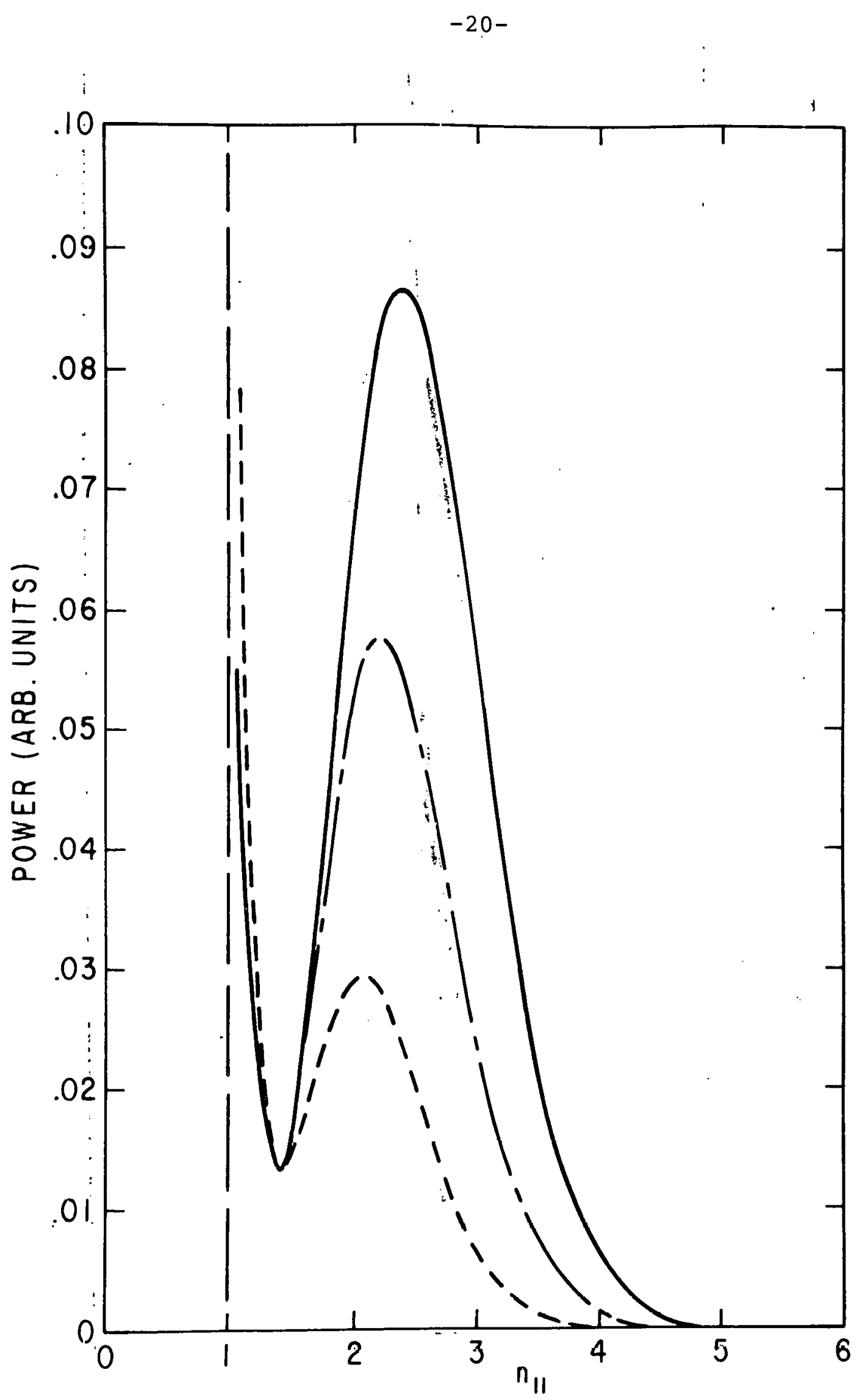

763474

Fig. $4(a)$ Energy flux spectrum radiated by 4 waveguides

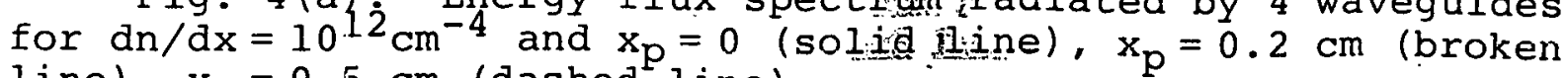
line), $x_{p}=0.5: \mathrm{cm}$ (dashed line). 


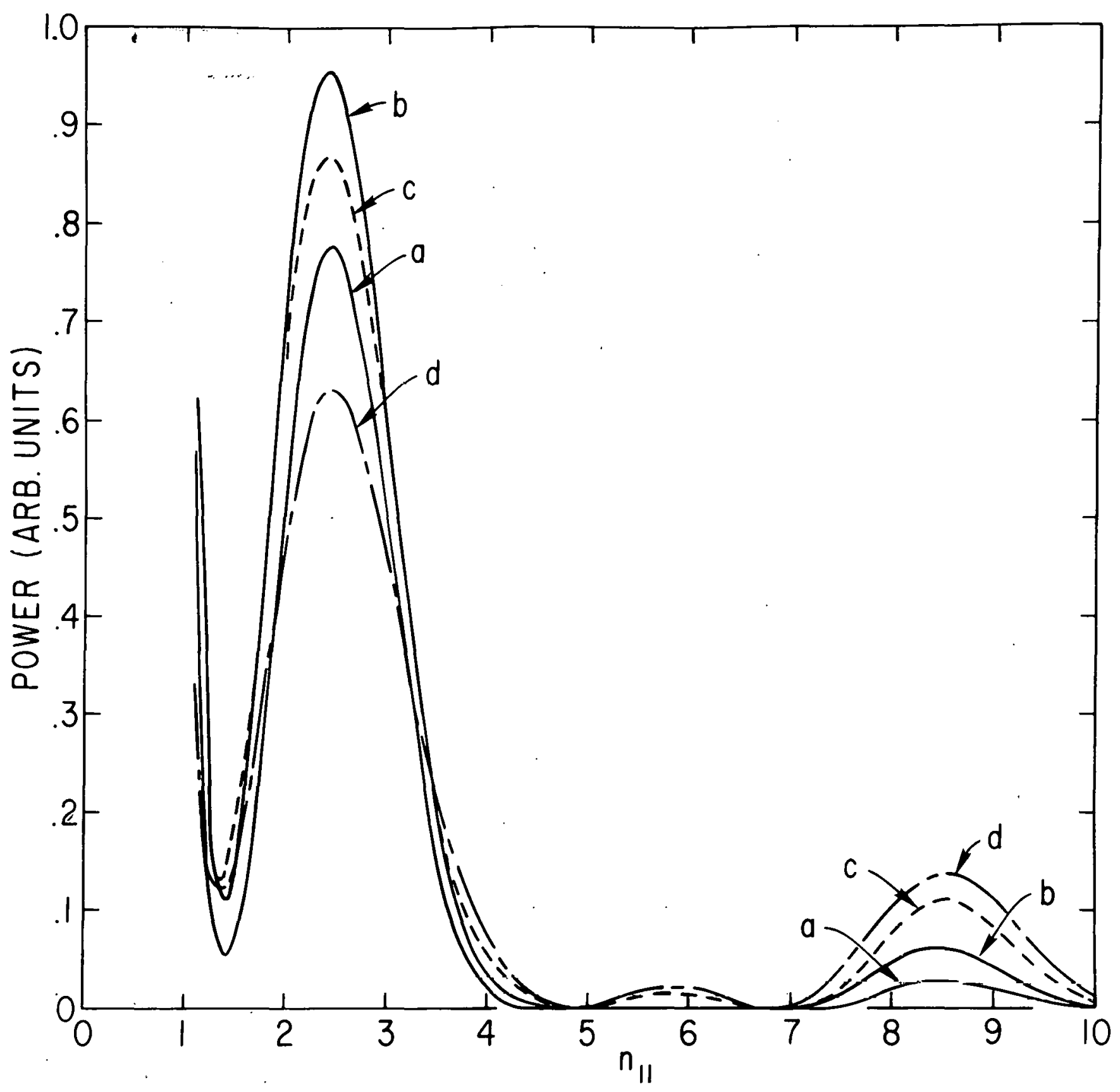

763475

Fig. 4(b). Energy flux spectrum radiated by 4 waveguides for $\mathrm{x}_{\mathrm{p}}=0$ and $\mathrm{dn} / \mathrm{dx}=10^{10} \mathrm{~cm}^{-4}(\mathrm{a}), \mathrm{dn} / \mathrm{dx}=10^{11} \mathrm{~cm}^{-4}(\mathrm{~b}), \mathrm{dn} / \mathrm{dx}=$ $10^{12} \mathrm{~cm}^{-4}$ (c), $\mathrm{dn} / \mathrm{dx}=10^{13} \mathrm{~cm}^{-4}$ (d). 


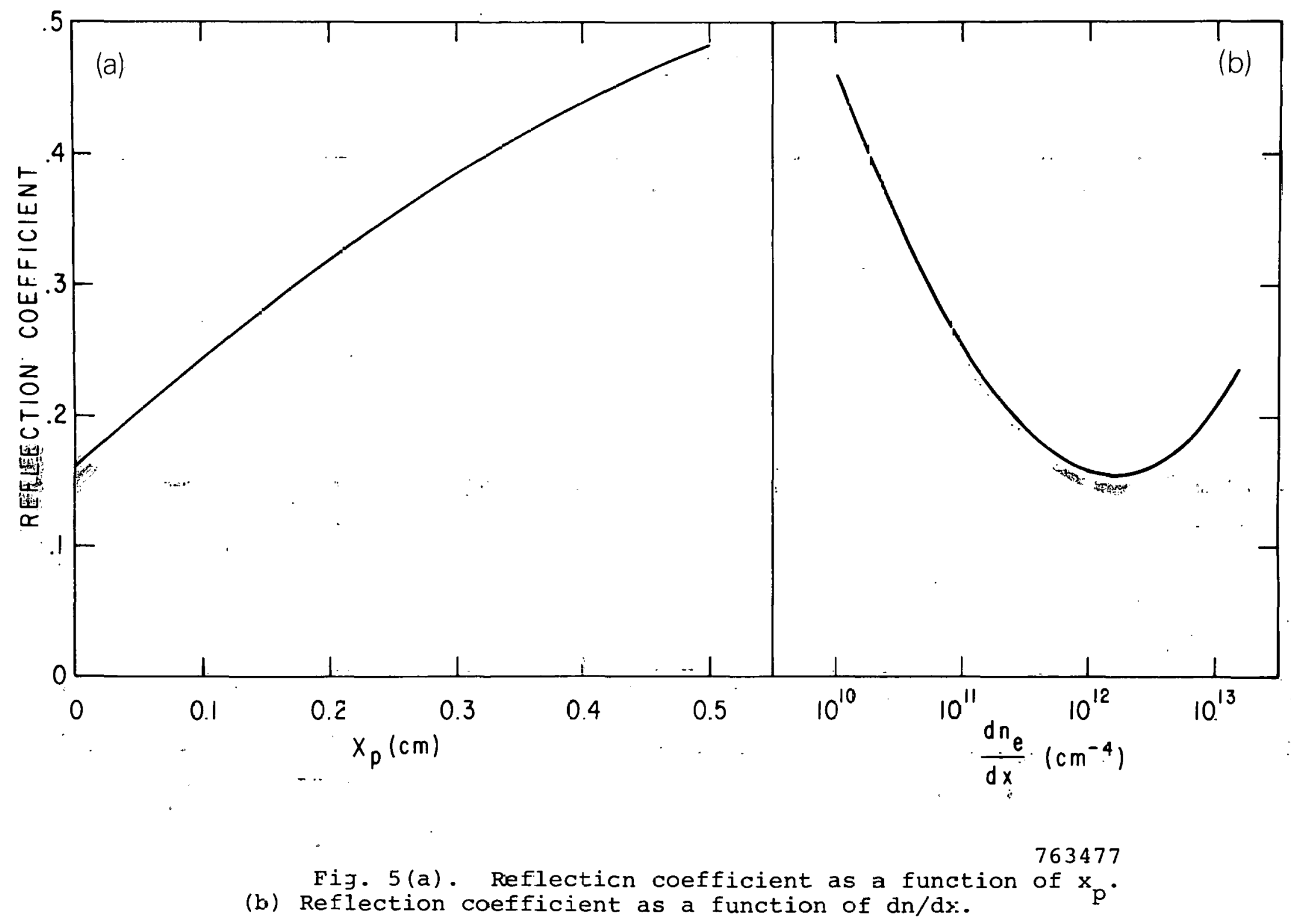

(b) Reflection coefficient as a function of $\mathrm{dn} / \mathrm{d}$ s. 


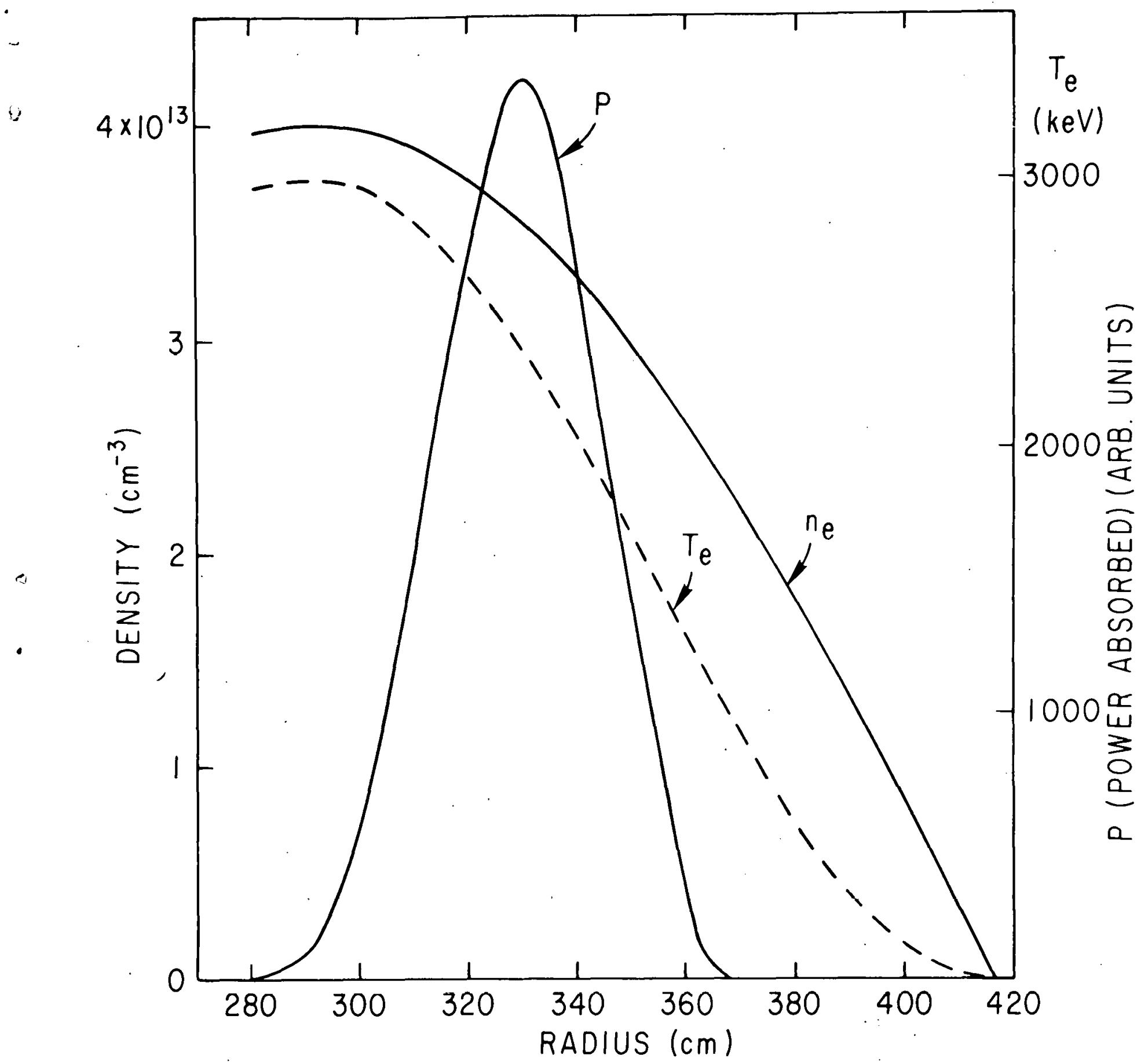

763478

Fig. 6. Power absorbed by electron Landau damping versus radius for the density and temperature profiles shown, $\mathrm{P}=\mathrm{dW} / \mathrm{dx}$. 